\title{
Frequency of CYP2C9 alleles in Koreans and their effects on losartan pharmacokinetics
}

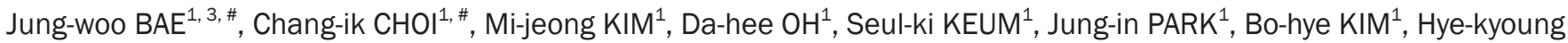
BANG ${ }^{1}$, Sung-gon $\mathrm{OH}^{1}$, Byung-sung KANG ${ }^{1}$, Hye-in LEE ${ }^{1}$, Yun-jeong LEE ${ }^{1}$, Hyun-joo PARK ${ }^{2}$, Hae-deun $\mathrm{KIM}^{2}$, Ji-hey HA ${ }^{2}$, Heejung SHIN ${ }^{2}$, Young-hoon $\mathrm{KIM}^{2}$, Han-sung $\mathrm{NA}^{2}$, Myeon-woo $\mathrm{CHUNG}^{2}$, Soon-young $\mathrm{HAN}^{2}$, Seung-hee $\mathrm{KIM}^{2}$, Choon-gon JANG ${ }^{1}$, Seok-yong LEE LE $^{1, *}$

${ }^{1}$ School of Pharmacy, Sungkyunkwan University, Suwon, 440-746, Korea; ${ }^{2}$ National Institute of Food and Drug Safety Evaluation, KFDA, Cheongwon-gun, 363-951, Korea; ${ }^{3}$ College of Pharmacy, Keimyung University, Daegu, 704-701, Korea

Aim: CYP2C9 enzyme metabolizes numerous clinically important drugs. The aim of this study is to investigate the frequencies of CYP2C9 genotypes and the effects of selected alleles on losartan pharmacokinetics in a large sample of the Korean population. Methods: The CYP2C9 gene was genotyped in 1796 healthy Korean subjects. CYP2C9 alleles (CYP2C9*1, *2, *3, and *13 alleles) were measured using polymerase chain reaction-restriction fragment length polymorphism (PCR-RFLP) assay and direct sequencing assay. The enzymatic activity of each CYP2C9 genotype was evaluated using losartan as the substrate.

Results: The frequencies of CYP2C9*1, *3, and *13 allele were 0.952 (95\% confidence interval 0.945-0.959), 0.044 (95\% Cl 0.037$0.051)$, and 0.005 (95\% Cl 0.003-0.007), respectively. The frequencies of the CYP2C9*1/*1, *1/*3, *1/*13, and *3/*3 genotypes were 0.904 (95\% Cl 0.890-0.918), 0.085 (95\% Cl 0.072-0.098), 0.009 (95\% Cl 0.005-0.013), and 0.001 (95\% Cl 0.000-0.002), respectively. In the pharmacokinetics studies, the $\mathrm{AUC}_{0-\infty}$ of losartan in CYP2C9 $3 / * 3$ subject was 1.42-fold larger than that in CYP2C9*1/*1 subjects, and the $\mathrm{AUC}_{0-\infty}$ of E-3174, a more active metabolite of losartan, in CYP2C9*3/*3 subject was only $12 \%$ of that in CYP2C9*1/*1 subjects.

Conclusion: The results confirmed the frequencies of CYP2C9 genotypes in a large cohort of Koreans, and detected the CYP $2 C 9 * 3 / * 3$ genotype. CYP2C9*3/*3 subjects metabolized much less losartan into E-3174 than CYP2C9*1/*1 subjects.

Keywords: CYP2C9; allele; genotype; Korean; pharmacokinetics; losartan

Acta Pharmacologica Sinica (2011) 32: 1303-1308; doi: 10.1038/aps.2011.100; published online 15 Aug 2011

\section{Introduction}

The cytochrome P450 (CYP) 2C9 enzyme oxidizes many clinically important compounds, including drugs with narrow therapeutic indexes such as warfarin, tolbutamide, and phenytoin, as well as other common drugs such as glibenclamide, glimepiride, glipizide, losartan, irbesartan, torsemide, and many anti-inflammatory drugs ${ }^{[1,2]}$. Genetic polymorphisms in enzymes that metabolize drugs are major determinants of variability in individual response. Thirty-five alleles of the CYP2C9 gene have been reported (http:/ / www. cypalleles.ki.se/cyp2c9.htm) and three of these, CYP2C9*1, $* 2$, and $* 3$, are frequently identified in most populations. The CYP2C9*2 allele is the most common deleterious allele among

\footnotetext{
\# These authors contributed equally to this work.

* To whom correspondence should be addressed.

E-mail sylee@skku.ac.kr

Received 2011-03-17 Accepted 2011-06-15
}

people of European descent, with a frequency of 0.080 to 0.191 . The CYP2C9*3 allele is less common $(0.033-0.162)^{[3]}$. In contrast, the CYP2C9*2 allele is rare among East Asians ${ }^{[3,4]}$, and $C Y P 2 C 9 * 3$ is more common than that in Europeans $(0.007 \text { to } 0.060)^{[5]}$. In addition, CYP2C9*3 homozygotes are seldom detected in East Asian populations ${ }^{[5]}$. CYP2C9*3 has the lowest metabolic activity in vitro, while CYP2C9*2 has an intermediate enzyme activity, and CYP2C9*1 has the highest activity ${ }^{[6]}$. Individuals with mutant CYP2C9 variants may not metabolize drugs adequately, leading to drug toxicity. Therefore, drug doses must be adjusted according to genotype. The frequencies of CYP2C9 alleles vary between populations, information that is useful for clinical pharmacotherapy. The frequencies of CYP2C9 alleles and genotypes in the Korean population have been calculated ${ }^{[5,7-9]}$, however, there are significant discrepancies in the reported CYP2C9*3 frequencies. Thus, we measured the CYP2C9 allele and genotype frequencies in a large Korean cohort, where we 
detected the $C Y P 2 C 9 * 3 / * 3$ genotype and analyzed the effects of the $C Y P 2 C 9 * 3 / * 3$ genotype on losartan pharmacokinetics.

\section{Materials and methods Subjects}

We enrolled 1796 unrelated healthy Korean volunteers in this genotyping study. Written informed consent was obtained from all volunteers.

\section{Genotyping tests}

Genomic DNA was isolated from peripheral blood leukocytes using the Wizard ${ }^{\circledR}$ Genomic DNA Kit (Promega, Madison, WI, USA) according to the manufacturer's instructions. Analyses of the CYP2C9*2, *3, and ${ }^{*} 13$ alleles were performed using polymerase chain reaction restriction fragment length polymorphism (PCR-RFLP), as described previously ${ }^{[5]}$. The CYP2C9*1 allele was assigned in the absence of other detectable alleles. The genotypes identified by PCR-RFLP were confirmed by sequence analysis. Exons and exon/intron junctions of the CYP2C9 gene were amplified as described with slight modifications $s^{[5,10]}$. The PCR products were purified using a PCR purification kit (AxyPrep ${ }^{\circledR}$ PCR Clean-up Kit, Axygen Bioscience Inc, Union City, CA, USA) and sequenced on an ABI3730 automatic sequencer (Applied Biosystems Inc, Foster City, CA, USA) using a BigDye Terminator Cycle Sequencing Ready Reaction Kit (Applied Biosystems Inc, Delaware, USA).

\section{Protocol for pharmacokinetic studies}

Thirteen healthy male Korean subjects with $C Y P 2 C 9^{*} 1 /{ }^{*} 1$ $(n=12)$ or CYP2C9*3/*3 $(n=1)$ genotypes were selected for a pharmacokinetic study of losartan. Although two subjects with $\mathrm{CYP} 2 \mathrm{C} 9 * 3 / * 3$ were detected, one did not provide written informed consent. Thus, only one subject with CYP2C9*3/*3 was enrolled in the pharmacokinetic study.

The subjects were between 20 and 26 years old and had body mass indexes between 21 and $25 \mathrm{~kg} / \mathrm{m}^{2}$. All subjects were healthy as defined by medical history, physical examination, and routine laboratory tests (blood chemistry, hematology, and urine analysis). The subjects were asked to refrain from ingesting medications, caffeine, grapefruit products, and alcoholic beverages and from smoking for at least 1 week before and during the study period. All subjects provided verbal and written informed consent after being given an explanation of the experimental procedures and purpose of the study. The institutional ethics committee of the School of Pharmacy, Sungkyunkwan University, Korea approved the study protocol. All procedures were performed in accordance with the recommendations of the Declaration of Helsinki on biomedical research involving human subjects.

On the day of the study, each subject received $50 \mathrm{mg}$ of losartan potassium (Cozaar ${ }^{\oplus}$, MSD-Korea, Seoul, Korea) orally with $240 \mathrm{~mL}$ of water after an overnight fast. The subjects maintained the fasting state for $4 \mathrm{~h}$ after receiving the drug. Before and at $0.5,1,1.5,2,3,4,6,8,10$, and $24 \mathrm{~h}$, venous blood samples $(10 \mathrm{~mL})$ were collected in heparinized tubes and centrifuged for $10 \mathrm{~min}$ at $3000 \mathrm{r} / \mathrm{min}$. The plasma was separated and stored at $-70^{\circ} \mathrm{C}$ until needed.

\section{Assay of losartan and E-3174 in plasma}

CYP2C9 metabolizes losartan to a more active metabolite, $\mathrm{E}-3174^{[11]}$. Thus, the losartan and E-3174 concentrations in the plasma were determined by HPLC with a fluorescence detector as previously reported with modifications ${ }^{[12]}$. Briefly, 1.0 $\mathrm{mL}$ of plasma, $150 \mathrm{ng}$ of valsartan (IS), and $200 \mu \mathrm{L}$ of $1 \mathrm{~mol} / \mathrm{L}$ phosphoric acid were mixed in a glass tube, and extracted with $7 \mathrm{~mL}$ of methyl tert-butyl ether (MTBE) with constant vigorous stirring for $1 \mathrm{~min}$. After centrifuging ( $2500 \mathrm{r} / \mathrm{min}$ for $10 \mathrm{~min}$ ), the organic layer was transferred to another tube with $200 \mu \mathrm{L}$ of $0.05 \mathrm{~mol} / \mathrm{L}$ sodium hydroxide and stirred vigorously for 1 $\mathrm{min}$. The samples were again centrifuged at $2500 \mathrm{r} / \mathrm{min}$ for $10 \mathrm{~min}$. The aqueous layer was collected, and residual MTBE was removed by nitrogen evaporation. The sodium hydroxide layer was acidified with $50 \mu \mathrm{L}$ of $0.2 \mathrm{~mol} / \mathrm{L}$ phosphoric acid and mixed. The aqueous fraction was washed by adding 6 $\mathrm{mL}$ of $n$-hexane and mixing for $1 \mathrm{~min}$. After centrifuging, the hexane was discarded, and residual $n$-hexane was removed by nitrogen evaporation. Methanol $(150 \mu \mathrm{L})$ was added to 250 $\mu \mathrm{L}$ of the re-extracted water phase, and $100 \mu \mathrm{L}$ of the resulting mixture was injected into the HPLC system. The HPLC system consisted of a Waters Model 515 HPLC pump, a Waters Model 717 Plus autosampler, a Waters 474 scanning fluorescence detector, and column oven (Waters, Milford, MA, USA). Separations were performed on a $5 \mu \mathrm{m}$ Luna CN column (4.5 $\mathrm{mm} \times 250 \mathrm{~mm}$; Phenomenex, Torrance, CA, USA). The mobile phase was $15 \mathrm{mmol} / \mathrm{L}$ phosphoric acid/acetonitrile (65:35, $v / v)$ adjusted to $\mathrm{pH} 3.0$ with $5 \mathrm{~mol} / \mathrm{L}$ sodium hydroxide at 1 $\mathrm{mL} / \mathrm{min}$. The effluents were detected by fluorescence with excitation at $250 \mathrm{~nm}$ and emission at $380 \mathrm{~nm}$. The standard curves for losartan and E-3174 were linear from 5 to 1000 $\mathrm{ng} / \mathrm{mL}\left(r^{2}>0.999\right)$. The mean accuracy for losartan and E-3174 were $90 \%-102 \%$ and $96 \%-101 \%$, respectively. The coefficients of variation (within-day and between-day precisions) of losartan and E-3174 were $<9 \%$ and 10\%, respectively.

\section{Pharmacokinetic analysis}

The pharmacokinetic parameters of losartan and E-3174 were calculated by non-compartmental methods from the blood sampling times, maximum plasma concentration $\left(C_{\max }\right)$, and time to reach $C_{\max }\left(t_{\max }\right)$ using the BA Calc 2007 analysis program (KFDA, Seoul, Korea). The area under the curve (AUC) for plasma concentration-time was calculated using the linear trapezoidal rule. The elimination rate constant $\left(k_{\mathrm{e}}\right)$ was determined by linear regression analysis of the log-linear portion of the plasma concentration-time curve. The AUC from 0 to infinity $\left(\mathrm{AUC}_{0-\infty}\right)$ was calculated as $\mathrm{AUC}_{0-\infty}=\mathrm{AUC}+C_{\mathrm{t}} / k_{\mathrm{e}}\left(C_{\mathrm{t}}\right.$ being the final plasma concentration). The half-life $\left(t_{1 / 2}\right)$ was calculated as $t_{1 / 2}=\ln 2 / k_{\mathrm{e}}$. The apparent oral clearance (CL/F) of losartan was calculated as $\mathrm{CL} / \mathrm{F}=$ Dose $/ \mathrm{AUC}_{0-\infty}$.

\section{Statistical analysis}

Data were compiled according to the genotype and allele frequencies. The frequencies of each allele are reported with 
95\% confidence intervals. Hardy-Weinberg equilibrium was evaluated by comparing the genotype frequencies with the expected values using a contingency table $\chi^{2}$ test. Statistical significance was determined by $\chi^{2}$ test; a $P$-value less than 0.05 was considered significant. The pharmacokinetic data are expressed as mean \pm SD.

\section{Results}

\section{Frequencies of CYP2C9 alleles and genotypes}

The estimated frequencies of the CYP2C9 alleles and genotypes in the Korean population are summarized in Table 1. The genotype frequency distribution did not deviate significantly from Hardy-Weinberg equilibrium. CYP2C9*1 was the most common allele $(0.952,95 \%$ CI: $0.945-0.959)$. The most common variant allele was CYP2C9*3 (0.044, 95\% CI: $0.037-$ 0.051). The CYP2C ${ }^{*} 1 / * 3$ frequency in this study was more than four times higher than previously reported ${ }^{[7]}(P<0.01$, Table 2). The CYP2C9*13 frequency in our sample was 0.005 (95\% CI: 0.003-0.007). There were 1624 subjects with the CYP2C9*1/*1 genotype (0.904, 95\% CI: 0.890-0.918), 153 with the CYP2C9*1/*3 genotype (0.085, 95\% CI: 0.072-0.098), 17 with the CYP2C9*1/ ${ }^{*} 13$ genotype $(0.009,95 \% \mathrm{CI}: 0.005-0.013)$, and 2 with the CYP2C $9 * 3 / 3$ genotype (0.001, 95\% CI: $0.000-0.002)$ (Table 1). The genotype results from PCR-RFLP corresponded with the sequencing results (data not shown).

Table 1. CYP2C9 allele (A) and genotype (B) frequencies in a large Korean sample. The expected genotype frequencies were calculated from the allele frequencies using the Hardy-Weinberg equation.

A

\begin{tabular}{lrcc}
\hline Allele & $n(3592)$ & Frequency & $95 \% \mathrm{Cl}$ \\
\hline CYP2C9*1 & 3418 & 0.952 & $0.945-0.959$ \\
CYP 2 C9*2 & 0 & 0.000 & $0.000-0.000$ \\
CYP 2 C9*3 & 157 & 0.044 & $0.037-0.051$ \\
CYP 2 C9*13 & 17 & 0.005 & $0.003-0.007$ \\
\hline
\end{tabular}

B

\begin{tabular}{|c|c|c|c|c|}
\hline Genotype & $\begin{array}{l}\text { Number of } \\
\text { subjects }\end{array}$ & $\begin{array}{l}\text { Observed } \\
\text { frequency }\end{array}$ & $95 \% \mathrm{Cl}$ & $\begin{array}{l}\text { Expected } \\
\text { frequency }\end{array}$ \\
\hline $\operatorname{CYP} 2 C 9 * 1 / * 1$ & 1624 & 0.904 & $0.890-0.918$ & 0.905 \\
\hline $\operatorname{CYP} 2 C 9 * 1 / * 3$ & 153 & 0.085 & $0.072-0.098$ & 0.083 \\
\hline CYP $2 C 9 * 1 / * 13$ & 17 & 0.009 & $0.005-0.013$ & 0.009 \\
\hline $\mathrm{CYP} 2 \mathrm{C} 9 * 3 / * 3$ & 2 & 0.001 & $0.000-0.002$ & 0.002 \\
\hline CYP $2 C 9 * 3 / * 13$ & 0 & 0.000 & $0.000-0.000$ & 0.000 \\
\hline CYP2C9*13/*13 & 0 & 0.000 & $0.000-0.000$ & 0.000 \\
\hline
\end{tabular}

The CYP2C9*3 allele frequency in our Korean sample was slightly (although not significantly) higher than in Chinese samples, and was significantly higher than in Japanese samples $(P<0.01)$ (Table 3$)$. The CYP2C9*13 allele frequency in our sample was slightly lower than in Chinese samples, and slightly higher than in Japanese samples, although these differences were not significant (Table 3).

\section{Pharmacokinetics of losartan}

The losartan and E-3174 pharmacokinetic parameters were measured in one subject with the CYP2C $9 * 3 /{ }^{*} 3$ genotype, a rare genotype in Koreans $(0.1 \%$, Table 1$)$. In this subject, the $C_{\max }$ and $\mathrm{AUC}_{0-\infty}$ of losartan were slightly higher and the $\mathrm{CL} / \mathrm{F}$ was lower than in CYP2C9*1/*1 subjects, but losartan metabolism to E-3174 was almost completely blocked (Figure 1, Table 4).
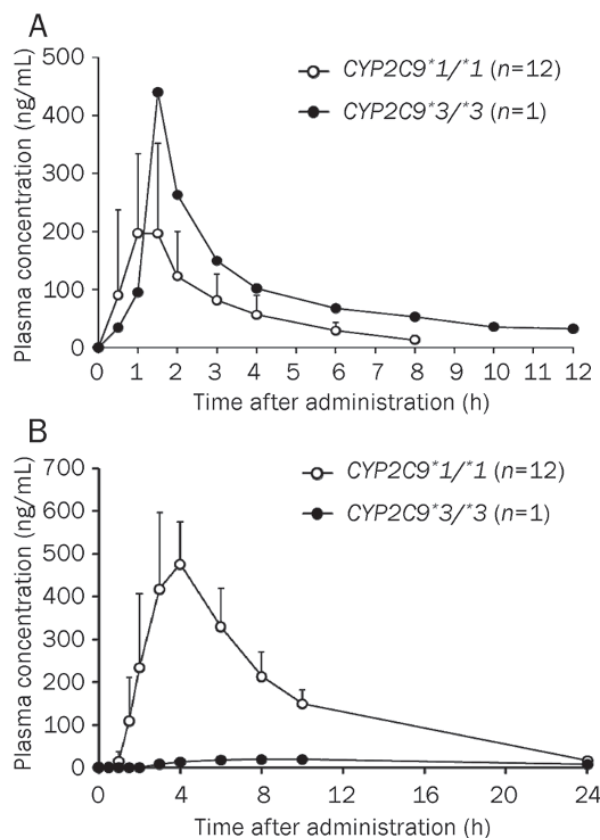

Figure 1. Plasma concentration-time profiles of losartan (A) and E-3174 (B) in subjects with the CYP2C9*1/*1 ( $n=12$, open circles) or CYP $2 C 9 * 3 / * 3$ ( $n=1$, closed circles) genotypes after administration of a single $50 \mathrm{mg}$ oral dose of losartan.

\section{Discussion}

CYP2C9 catalyzes phase I metabolism for approximately $15 \%-20 \%$ of the drugs subject to this reaction. The CYP2C9 allelic variants CYP2C9*2, CYP2C9*3, and CYP2C9*13 code for enzymes with approximately $10 \%-40 \%, 5 \%-15 \%$, and $1 \%-12 \%$ of the activity of CYP2C9*1, respectively ${ }^{[4,10,29]}$. The CYP2C9*2 allele is the most common variant allele among people of European descent with a frequency of approximately $0.132^{[4,9,16,30]}$. In contrast, the CYP2C9*2 allele is rare in East Asians ${ }^{[3]}$ (Table $3)$. To date, the CYP2C9*2 allele has been detected in only two East Asian subjects, both Chinese with the CYP $2 C 9^{*} 1 /{ }^{*} 2$ genotype ${ }^{[9,16]}$. We did not detect the CYP2C9*2 allele in our sample of 2154 Koreans (Table 3).

Functionally, the CYP2C9*3 allele has the lowest metabolic activity in vitro, while CYP2C9*2 lies between $C Y P 2 C 9 * 3$ and CYP2C $9^{*} 1^{[6]}$. Europeans have significant heterogeneity in 
Table 2. Comparisons of reported CYP2C9 allele frequencies in Koreans.

\begin{tabular}{|c|c|c|c|c|c|}
\hline$n$ & $\star 1$ & $\star 2$ & $\star 3$ & $\star 13$ & Reference \\
\hline 716 & $0.934(0.916-0.952)$ & $0.000(0.000-0.000)$ & $0.060(0.043-0.077)$ & $0.006(0.000-0.012)$ & [5] \\
\hline 1148 & 0.989 (0.983-0.995) & $0.000(0.000-0.000)$ & $0.011^{\mathrm{c}}(0.005-0.017)$ & ND & [7] \\
\hline 590 & $0.947(0.929-0.965)$ & $0.000(0.000-0.000)$ & $0.051(0.033-0.069)$ & $0.002(0.000-0.006)$ & [13] \\
\hline
\end{tabular}

Values in parentheses represent 95\% confidence intervals; $n=$ number of alleles; differences between frequency data were calculated using the chisquare test. ND=Not determined. ${ }^{c} P<0.01$ between present and previous studies [7] (95\% $\mathrm{Cl}$ on the difference $\left.0.024-0.042\right)$.

Table 3. CYP2C9 allele frequencies in East Asian populations.

\begin{tabular}{|c|c|c|c|c|c|c|}
\hline \multirow{2}{*}{ Populations } & \multirow{2}{*}{$n$} & \multicolumn{4}{|c|}{ CYP2C9 allele frequency } & \multirow{2}{*}{ Reference } \\
\hline & & $\star 1$ & $\star 2$ & $\star 3$ & $\star 13$ & \\
\hline Korean & 4308 & $0.949(0.942-0.956)$ & $0.000(0.000-0.000)$ & $0.046(0.040-0.052)$ & $0.005(0.003-0.007)$ & Present study ${ }^{\#}$ \\
\hline \multirow[t]{8}{*}{ Chinese } & 2174 & 0.964 & 0.000 & 0.036 & ND & {$[14]$} \\
\hline & 1008 & 0.967 & 0.000 & 0.033 & ND & [15] \\
\hline & 788 & 0.963 & 0.001 & 0.036 & ND & [16] \\
\hline & 230 & 0.983 & 0.000 & 0.017 & ND & [18] \\
\hline & 204 & 0.951 & 0.000 & 0.049 & ND & [19] \\
\hline & 796 & 0.958 & 0.001 & 0.041 & ND & [9] \\
\hline & 658 & - & - & - & 0.006 & [20] \\
\hline & 294 & - & - & - & 0.010 & [21] \\
\hline Sum of Chinese & $5938(952)^{*}$ & $0.964(0.959-0.969)$ & $0.003(0.002-0.004)$ & $0.035(0.030-0.040)$ & $0.007(0.003-0.011)$ & \\
\hline & 1200 & 0.979 & 0.000 & 0.021 & ND & [23] \\
\hline & 524 & 0.968 & 0.000 & 0.031 & 0.002 & [10] \\
\hline & 436 & 0.979 & 0.000 & 0.021 & ND & [24] \\
\hline & 400 & 0.965 & 0.000 & 0.035 & ND & {$[8]$} \\
\hline & 280 & 0.982 & 0.000 & 0.018 & ND & [25] \\
\hline & 236 & 0.970 & 0.000 & 0.030 & ND & [26] \\
\hline & 246 & 0.955 & 0.000 & 0.045 & ND & [27] \\
\hline & 294 & 0.993 & 0.000 & 0.007 & ND & [28] \\
\hline Sum of Japanese & $6064(524)^{\&}$ & $0.972(0.968-0.976)$ & $0.000(0.000-0.000)$ & $0.028^{\mathrm{c}}(0.024-0.032)$ & $0.002(0.000-0.005)$ & \\
\hline
\end{tabular}

Values in parentheses represent $95 \%$ confidence intervals; $n=$ number of alleles; differences between frequency data were calculated using the chisquare test. $\mathrm{ND}=$ Not determined.

\#, Data were combined with a previous study ${ }^{[5]}$.

*, \&, Values in parentheses represent the total numbers with the CYP2C9*13 allele.

${ }^{c} P<0.01$ between present study and sum of Japanese (95\% $\mathrm{Cl}$ on the difference $\left.0.010-0.026\right)$.

the $\mathrm{CYP} 2 \mathrm{C} 9 * 2$ allele frequency (ranging from 0.033 to 0.162 ), whereas the $C Y P 2 C 9 * 3$ allele is less common ${ }^{[6]}$. The CYP2C9*3 frequency in Koreans was previously reported as $0.011^{[7]}$, but we previously found it to be $0.060^{[5]}$. Because these results are so different, an additional study was needed. In addition, the first study found no difference in the CYP2C9*3 frequency between Korean and Japanese samples, but our previous report $\mathrm{did}^{[5]}$. In Korean population (2154 unrelated subjects), the $C Y P 2 C 9^{*} 3$ frequency was 0.046 , significantly higher
$(P<0.001)$ than the mean frequency in Japanese $(0.028)$, but similar to the frequency in Chinese (0.035) (Table 3). Because the CYP2C9 allele and genotype frequencies vary among studies, a large sample, such as ours, should reflect actual genotype frequencies. A recent study of 295 Koreans reported a CYP2C9*3 frequency similar to the one found in this study ${ }^{[13]}$, but the $C Y P 2 C 9^{*} 13$ frequency was lower. The CYP2C9*13 frequency in our study was 2.5 -fold higher. Because the number of samples in this study $(n=3592)$ was much higher 
Table 4. Pharmacokinetic parameters of oral losartan in subjects with the CYP 2 C $* 1 / * 1$ and CYP 2 C $9 * 3 / 3$ genotypes. Mean \pm SD.

\begin{tabular}{lcc}
\hline \multicolumn{1}{c}{ Variable } & \multicolumn{1}{c}{$\begin{array}{c}\mathrm{CYP} 2 \mathrm{Cg} * 1 / * 1 \\
(n=12)\end{array}$} & $\begin{array}{c}\mathrm{CYP} 2 \mathrm{C9} * 3 / * 3 \\
(n=1)\end{array}$ \\
\hline Losartan & & \\
$C_{\max }(\mathrm{ng} / \mathrm{mL})$ & $235.1 \pm 98.4(172.6,297.6)$ & 440.2 \\
$t_{1 / 2}(\mathrm{~h})$ & $1.92 \pm 0.76(1.44,2.40)$ & 4.72 \\
$\mathrm{CL} / \mathrm{F}(\mathrm{L} / \mathrm{h})$ & $0.094 \pm 0.018(0.082,0.106)$ & 0.037 \\
$\mathrm{AUC} C_{0-\infty}(\mathrm{ng} \cdot \mathrm{h} / \mathrm{mL})$ & $552.2 \pm 102.2(487.3,617.1)$ & 1334.9 \\
$\mathrm{E}-3174$ & & \\
$C_{\max }(\mathrm{ng} / \mathrm{mL})$ & $524.3 \pm 84.1(470.8,577.8)$ & 19.1 \\
$t_{1 / 2}(\mathrm{~h})$ & $4.29 \pm 0.40(4.04,4.54)$ & 10.56 \\
$\mathrm{AUC}_{0-\infty}(\mathrm{ng} \cdot \mathrm{h} / \mathrm{mL})$ & $3471.9 \pm 466.2(3175.7,3768.1)$ & 400.9 \\
\hline
\end{tabular}

Values in parentheses represent $95 \%$ confidence intervals. $C_{\text {max }}$, maximum plasma concentration; $\mathrm{AUC}_{0-\infty}$, area under the plasma concentration-time curve from time 0 to infinity; $t_{1 / 2}$, elimination half-life; $C L / F$, apparent oral clearance; $n$, number of subjects.

than that in other study $(n=590)^{[13]}$, this study may serve more reliable information on the frequencies of CYP2C9 alleles in Korean population.

The CYP2C9* 13 allele was first identified in a Chinese sample, and the CYP2C9*3/*13 genotype confers a remarkable reduction in metabolic activity ${ }^{[21]}$. In this study, 17 of 1796 subjects had the CYP2C9*1/*13 genotype, while CYP2C ${ }^{*} 13 /{ }^{*} 13$ and ${ }^{*} 3 /{ }^{*} 13$ were not found (Table 1 ). The CYP2C ${ }^{*} 13$ variant has impaired activity towards a number of substrates in vivo ${ }^{[20,29,31]}$, and has only been found in East Asians (Table 3). It is apparently absent from African-American, European, Hispanic, and Ashkenazi Jewish populations ${ }^{[32]}$.

In this study, two subjects were homozygous for CYP2C9*3*3, but one did not provide written informed consent for inclusion in the pharmacokinetic study. We evaluated the enzymatic activity of the remaining CYP2C $9 * 3 / * 3$ homozygote using losartan. In the CYP2C ${ }^{*} 3 / * 3$ subject, the $C_{\max }\left(187 \%\right.$ of $\left.C Y P 2 C 9^{*} 1 /{ }^{*} 1\right)$ and AUC $\left(242 \%\right.$ of $\left.C Y P 2 C 9^{*} 1 /{ }^{*} 1\right)$ of losartan increased and the $C_{\max }\left(3.6 \%\right.$ of $\left.C Y P 2 C 9^{*} 1{ }^{*} 1\right)$ and AUC $\left(11.5 \%\right.$ of $\left.C Y P 2 C 9^{*} 1{ }^{*} 1\right)$ of E-3174 decreased compared with $C Y P 2 C 9^{*} 1 /{ }^{*} 1$ subjects. In the CYP2C9*3/*3 subject, E-3174 formation from losartan decreased markedly compared to CYP2C9 ${ }^{*} 1 /{ }^{*} 1$ subjects, therefore the $\mathrm{AUC}_{0-\infty}$ was about $1 / 9$ th that of $C Y P 2 C 9^{*} 1{ }^{*} 1$ subjects. These results agree with a previous report from Sweden ${ }^{[33]}$. Although both losartan and E-3174 block angiotensin II receptors, E-3174 is at least 10 -fold more potent than losartan ${ }^{[34]}$, and the clinical effects of losartan are mainly due to E-3174. Thus, losartan may have reduced antihypertensive effects in $C Y P 2 C C^{*} 3 / 3$ subjects than in $C Y P 2 C 9^{*} 1 /{ }^{*} 1$ subjects. Therefore, $C Y P 2 C 9 * 3 * * 3$ patients with hypertension might do well to take other hypertensive agents that are not metabolized by CYP2C9. In previous studies, losartan conversion to E-3174 was significantly reduced in the CYP2C ${ }^{*} 1 / * 3\left(50 \%-95 \% \text { of that in CYP2C }{ }^{*} 1 /{ }^{*} 1\right)^{[20,33,35,36]}$ and ${ }^{*} 1 /{ }^{*} 13$ genotypes $\left(62 \% \text { of that in } C Y P 2 C 9^{*} 1 /{ }^{*} 1\right)^{[2]}$. Because the $\mathrm{AUC}_{0-\infty}$ of E-3174 did not differ significantly between
CYP2C9*1/* 1 subjects and CYP2C9*3 or * 13 heterozygotes, these genotypes did not affect the clinical effects of losartan. Because the CYP2C9*3/3 genotype has almost no enzyme activity, the use of warfarin, phenytoin, and oral hypoglycemic agents might be hazardous ${ }^{[1,2,6]}$.

In summary, the CYP2C $9^{*} 3$ frequency in the Korean population was estimated to be 0.044 (95\% CI $0.037-0.051)$ and the CYP2C9*13 frequency was estimated to be $0.005(95 \% \mathrm{CI}$ $0.003-0.007)$. Only four genotypes $\left(C Y P 2 C{ }^{*} 1 /{ }^{*} 1,{ }^{*} 1 /{ }^{*} 3,{ }^{*} 1 /{ }^{*} 13\right.$, and $* 3 / * 3$ ) were found in a large Korean sample. CYP2C9*3/*3 subjects formed markedly less E-3174 from losartan than CYP2C9* $1 /{ }^{*} 1$ subjects, suggesting a profound reduction in antihypertensive effect of losartan in this genotype.

\section{Acknowledgements}

This study was supported by a grant (№ 09172KFDA646) from Korea Food \& Drug Administration in 2009-2010.

\section{Author contribution}

Jung-woo BAE performed genotyping and PK study and wrote the paper. Chang-ik CHOI performed genotyping and PK study and wrote the paper. Mi-jeong KIM performed volunteer recruiting and genotyping. Da-hee $\mathrm{OH}$ performed genotyping and PK study. Seul-ki KEUM performed genotyping and PK study. Jung-in PARK performed volunteer recruiting and genotyping. Bo-hye KIM performed genotyping and PK study. Hye-kyoung BANG performed volunteer recruiting and genotyping. Sung-gon $\mathrm{OH}$ performed genotyping and PK study. Byung-sung KANG performed volunteer recruiting and genotyping. Hye-in LEE determined losartan concentration in plasma. Yun-jeong LEE performed volunteer recruiting and genotyping. Hyun-joo PARK performed volunteer recruiting and genotyping. Haedeun KIM performed volunteer recruiting and genotyping. Jihey HA performed volunteer recruiting and genotyping. Heejung SHIN performed volunteer recruiting and genotyping. Young-hoon KIM performed volunteer recruiting and genotyping. Han-sung NA performed volunteer recruiting and genotyping. Myeon-woo CHUNG performed volunteer recruiting and genotyping. Soon-young HAN determined losartan concentration in plasma. Seung-hee KIM determined losartan concentration in plasma. Choon-gon JANG analyzed data. Seok-yong LEE designed research and wrote the paper.

\section{References}

1 Miners JO, Birkett DJ. Cytochrome P4502C9: an enzyme of major importance in human drug metabolism. Br J Clin Pharmacol 1998; 45: 525-38.

2 Schwarz UI. Clinical relevance of genetic polymorphisms in the human CYP2C9 gene. Eur J Clin Invest 2003; 33: 23-30.

3 García-Martín E, Martínez C, Ladero JM, Agúndez JA. Interethnic and intraethnic variability of CYP2C8 and CYP2C9 polymorphisms in healthy individuals. Mol Diagn Ther 2006; 10: 29-40.

4 Scordo MG, Caputi AP, D'Arrigo C, Fava G, Spina E. Allele and genotype frequencies of CYP2C9, CYP2C19 and CYP2D6 in an Italian population. Pharmacol Res 2004; 50: 195-200. 
5 Bae JW, Kim HK, Kim JH, Yang SI, Kim MJ, Jang CG, et al. Allele and genotype frequencies of CYP2C9 in a Korean population. $\mathrm{Br} J$ Clin Pharmacol 2005; 60: 418-22.

6 Lee CR, Goldstein JA, Pieper JA. Cytochrome P450 2 C9 polymorphisms: a comprehensive review of the in-vivo and human data. Pharmacogenetics 2002; 12: 251-63.

7 Yoon YR, Shon JH, Kim MK, Lim YC, Lee HR, Park JY, et al. Frequency of cytochrome $\mathrm{P} 4502 \mathrm{C9}$ mutant alleles in a Korean population. $\mathrm{Br} \mathrm{J}$ Clin Pharmacol 2001; 51: 277-80.

8 Myrand SP, Sekiguchi K, Man MZ, Lin X, Tzeng RY, Teng CH, et al. Pharmacokinetics/genotype associations for major cytochrome P450 enzymes in native and first- and third-generation Japanese populations: comparison with Korean, Chinese, and Caucasian populations. Clin Pharmacol Ther 2008; 84: 347-61.

9 Man M, Farmen M, Dumaual C, Teng CH, Moser B, Irie S, et al. Genetic variation in metabolizing enzyme and transporter genes: comprehensive assessment in 3 major East Asian subpopulations with comparison to Caucasians and Africans. J Clin Pharmacol 2010; 50 : 929-40.

10 Maekawa K, Fukushima-Uesaka H, Tohkin M, Hasegawa R, Kajio H, Kuzuya $\mathrm{N}$, et al. Four novel defective alleles and comprehensive haplotype analysis of CYP2C9 in Japanese. Pharmacogenet Genomics 2006; 16: 497-514.

11 Stearns RA, Chakravarty PK, Chen R, Chiu SH. Biotransformation of losartan to its active carboxylic acid metabolite in human liver microsomes. Role of cytochrome $\mathrm{P} 4502 \mathrm{C}$ and $3 \mathrm{~A}$ subfamily members. Drug Metab Dispos 1995; 23: 207-15.

12 Ritter MA, Furtek Cl, Lo MW. An improved method for the simultaneous determination of losartan and its major metabolite, EXP3174, in human plasma and urine by high-performance liquid chromatography with fluorescence detection. J Pharm Biomed Anal 1997; 15 : 1021-9.

13 Lee HW, Lim MS, Lee J, Jegal MY, Kim DW, Lee WK, et al. Frequency of CYP2C9 variant alleles, including CYP2C9*13 in a Korean population and effect on glimepiride pharmacokinetics. J Clin Pharm Ther 2011. doi: 10.1111/j.1365-2710.2010.01238.x.

14 Hong X, Zhang S, Mao G, Jiang S, Zhang Y, Yu Y, et al. CYP2C9*3 allelic variant is associated with metabolism of irbesartan in Chinese population. Eur J Clin Pharmacol 2005; 61: 627-34.

15 Yu BN, Luo CH, Wang D, Wang A, Li Z, Zhang W, et al. CYP2C9 allele variants in Chinese hypertension patients and healthy controls. Clin Chim Acta 2004; 348: 57-61.

16 Yang JQ, Morin S, Verstuyft C, Fan LA, Zhang Y, Xu CD, et al. Frequency of cytochrome P450 2C9 allelic variants in the Chinese and French populations. Fund Clin Pharmacol 2003; 17: 373-6.

17 Chen K, Wang R, Wen SY, Li J, Wang SQ. Relationship of P450 2 C9 genetic polymorphisms in Chinese and the pharmacokinetics of tolbutamide. J Clin Pharm Ther 2005; 30: 241-9.

18 Wang SL, Huang J, Lai MD, Tsai JJ. Detection of CYP2C9 polymorphism based on the polymerase chain reaction in Chinese. Pharmacogenetics 1995; 5: 37-42.

19 Gaedigk A, Casley WL, Tyndale RF, Sellers EM, Jurima-Romet M, Leeder JS. Cytochrome P-4502C9 (CYP2C9) allele frequencies in Canadian Native Indian and Inuit populations. Can J Physiol Pharmacol 2001; 79: 841-7.

20 Li Z, Wang G, Wang LS, Zhang W, Tan ZR, Fan L, et al. Effects of the CYP2C9*13 allele on the pharmacokinetics of losartan in healthy male subjects. Xenobiotica 2009; 39: 788-93.

21 Si D, Guo Y, Zhang Y, Yang L, Zhou H, Zhong D. Identification of a novel variant CYP2C9 allele in Chinese. Pharmacogenetics 2004; 14 : 465-9.

22 Yin T, Maekawa K, Kamide K, Saito Y, Hanada H, Miyashita K, et al. Genetic variations of CYP2C9 in 724 Japanese individuals and their impact on the antihypertensive effects of losartan. Hypertens Res 2008; 31: 1549-57.

23 Yoshizawa M, Hayashi H, Tashiro Y, Sakawa S, Moriwaki H, Akimoto T, et al. Effect of VKORC1-1639 G>A polymorphism, body weight, age, and serum albumin alterations on warfarin response in Japanese patients. Thromb Res 2009; 124: 161-6.

24 Nasu K, Kubota T, Ishizaki T. Genetic analysis of CYP2C9 polymorphism in a Japanese population. Pharmacogenetics 1997; 7: 405-9.

25 Kimura M, leiri I, Mamiya K, Urae A, Higuchi S. Genetic polymorphism of cytochrome P-450s, CYP2C19, and CYP2C9 in a Japanese population. Ther Drug Monitor 1998; 20: 243-7.

26 Obayashi K, Nakamura K, Kawana J, Ogata H, Hanada K, Kurabayashi $\mathrm{M}$, et al. VKORC1 gene variations are the major contributors of variation in warfarin dose in Japanese patients. Clin Pharmacol Ther 2006; 80: 169-78.

27 Xie HG, Prasad H, Landau R, Kim RB, Cai WM, leiri I, et al. Frequency of the defective CYP2C9 variant alleles in different ethinc groups [abstract]. Clin Pharmacol Ther 2002; 71: P102.

28 Nakai K, Habano W, Nakai K, Fukushima N, Suwabe A, Moriya S, et al. Ethnic differences in CYP2C9*2 (Arg144Cys) and CYP2C9 *3 (lle359Leu) genotypes in Japanese and Israeli populations. Life Sci 2005; 78: 107-11.

29 Guo Y, Zhang Y, Wang Y, Chen X, Si D, Zhong D, et al. Role of CYP2C9 and its variants (CYP2C9*3 and CYP2C9*13) in the metabolism of lornoxicam in humans. Drug Metab Dispos 2005; 33: 749-53.

30 Yasar U, Eliasson E, Dahl ML, Johansson I, Ingelman-Sundberg M, Sjöqvist F. Validation of methods for CYP2C9 genotyping: frequencies of mutant alleles in a Swedish population. Biochem Biophys Res Commun 1999; 254: 628-31.

31 Bae JW, Choi Cl, Jang CG, Lee SY. Effects of CYP2C9*1/*13 on the pharmacokinetics and pharmacodynamics of meloxicam. $\mathrm{Br} J$ Clin Pharmacol 2011; 71: 550-5.

32 Scott SA, Khasawneh R, Peter I, Kornreich R, Desnick RJ. Combined CYP2C9, VKORC1 and CYP4F2 frequencies among racial and ethnic groups. Pharmacogenomics 2010; 11: 781-91.

33 Yasar U, Forslund-Bergengren C, Tybring G, Dorado P, Llerena A, Sjöqvist $F$, et al. Pharmacokinetics of losartan and its metabolite E-3174 in relation to the CYP2C9 genotype. Clin Pharmacol Ther 2002; 71: 89-98.

34 Sachinidis A, Ko Y, Weisser P, Meyer zu Brickwedde MK, Düsing R, Christian R, et al. EXP3174, a metabolite of losartan [MK 954, DuP 753] is more potent than losartan in blocking the angiotensin IIinduced responses in vascular smooth muscle cells. J Hypertens 1993; 11: 155-62.

35 Sekino K, Kubota T, Okada Y, Yamada Y, Yamamoto K, Horiuchi R, et al. Effect of the single CYP2C9*3 allele on pharmacokinetics and pharmacodynamics of losartan in healthy Japanese subjects. Eur J Clin Pharmacol 2003; 59: 589-92.

36 Lee CR, Pieper JA, Hinderliter AL, Blaisdell JA, Goldstein JA. Losartan and E3174 pharmacokinetics in cytochrome P450 2C9*1/*1, *1/*2, and $* 1 / * 3$ individuals. Pharmacotherapy 2003; 23: 720-5. 